\title{
Understanding the correlation between oxide ion mobility and site distributions in $\mathrm{Ba}_{3} \mathrm{NbWO}_{8.5}$
}

\author{
Josie E. Auckett, Matthias J. Gutmann \\ and Ivana Radosavljevic Evans
}

\section{Published version information}

Citation: JE Auckett, MJ Gutmann and IR Evans. 'Understanding the correlation between oxide ion mobility and site distributions in $\mathrm{Ba}_{3} \mathrm{NbWO}_{8.5}$.' Inorg Chem, vol. 59, no. 19 (2020): 14245-14250.

\section{DOI: $10.1021 /$ acs.inorgchem.0c02035}

This document is the Accepted Manuscript version of a Published Work that appeared in final form in Inorganic Chemistry, copyright (c) American Chemical Society after peer review and technical editing by the publisher. To access the final edited and published work see DOI above.

Please cite only the published version using the reference above. This is the citation assigned by the publisher at the time of issuing the AAM. Please check the publisher's website for any updates. 


\title{
Understanding the correlation between oxide ion mobility and site distributions in $\mathrm{Ba}_{3} \mathrm{NbWO}_{8.5}$
}

Josie E. Auckett, ${ }^{a *}$ Matthias J. Gutmann ${ }^{b}$ and Ivana Radosavljevic Evans ${ }^{a}$

${ }^{a}$ Department of Chemistry, Durham University, South Road, Durham DH1 3LE, United

Kingdom

${ }^{\mathrm{b}}$ Rutherford Appleton Laboratory, ISIS Facility, Chilton Didcot, Oxfordshire OX11 0QX, United Kingdom

\begin{abstract}
A correlation between oxygen site distributions and ionic conductivity has been established in the recently discovered family of oxide-ion conductors $\mathrm{Ba}_{3} M_{2} \mathrm{O}_{8.5 \pm \delta}(M=\mathrm{Nb}, \mathrm{V}, \mathrm{Mo}, \mathrm{W})$. We rationalise this observation on the basis of structural insights gained from the first single-crystal neutron diffraction data collected for a member of this family, $\mathrm{Ba}_{3} \mathrm{NbWO}_{8.5}$, and theoretical considerations of bonding and $\mathrm{O}$ site energies.
\end{abstract}

Introduction 
The ionic conductors with general formula $\mathrm{Ba}_{3} M_{2} \mathrm{O}_{8.5 \pm \delta}(M=\mathrm{Nb}, \mathrm{V}, \mathrm{Mo}, \mathrm{W})$ have recently attracted attention due to their promising conductivity at temperatures considered "moderate" for applications such as electrolytes in solid-oxide fuel cells (SOFCs). ${ }^{1-4}$ The best-performing material in this class reported so far, $\mathrm{Ba}_{3} \mathrm{Nb}_{0.9} \mathrm{~V}_{0.1} \mathrm{MoO}_{8.5}$, has ionic conductivity that reaches $0.01 \mathrm{~S} / \mathrm{cm}$ at $600{ }^{\circ} \mathrm{C}^{4}$ This conductivity compares favourably with that of yttria-stabilised zirconia and the best performers in the scheelite, ${ }^{5-6}$ apatite ${ }^{7-8}$ and brownmillerite ${ }^{9-10}$ structural families; it is very similar to $\mathrm{La}_{2} \mathrm{Mo}_{2} \mathrm{O}_{9}{ }^{11}{ }^{11} \mathrm{Na}_{0.5} \mathrm{Bi}_{0.5} \mathrm{TiO}_{3}{ }^{12}$ and melilite-type $\mathrm{La}_{1.54} \mathrm{Sr}_{0.46} \mathrm{Ga}_{3} \mathrm{O}_{7.27}{ }^{13}$ but lower than the best $\mathrm{Bi}_{2} \mathrm{O}_{3}$-based oxide ion conductors. ${ }^{14}$ However, it has been demonstrated that $\mathrm{Ba}_{3} M_{2} \mathrm{O}_{8.5 \pm \delta}$ materials have the capacity for performance enhancement by compositional tuning. ${ }^{4}$

The $\mathrm{Ba}_{3} M_{2} \mathrm{O}_{8.5 \pm \delta}$ series has been shown to adopt a 9R-perovskite-like structure with a high degree of cationic and anionic disorder. ${ }^{15-16}$ This disorder is believed to play a key role in facilitating oxide ion mobility, ${ }^{4}, 17$ though the complexity of characterising and describing the disordered ionic arrangements is highlighted in experimental studies of the average and local structures of these materials.

In the ideal 9R perovskite structure $\left(A_{3} M_{3} \mathrm{O}_{9}\right)$, triplets of $M \mathrm{O}_{6}$ octahedra are arranged in facesharing stacks known as "trimers", where the terminating octahedra of each trimer share corners with three others. In the $\mathrm{Ba}_{3} M_{2} \mathrm{O}_{8.5 \pm \delta}$ structure, two $M$ cations are distributed between the three polyhedra in each trimer, with the majority of ions occupying end units (M1) and a relatively low proportion occupying the middle unit (M2). The M1 polyhedra in $\mathrm{Ba}_{3} M_{2} \mathrm{O}_{8.5 \pm \delta}$ also exhibit a mixture of 6-fold and lower coordination numbers due to the loss of some oxygen from the ideal structure to balance the lower $M$ cation content. Notably, several studies have reported that the distribution of oxide ions between the ideal (corner-shared) $\mathrm{O} 2$ site and a non-shared $\mathrm{O} 3$ site is correlated with the degree of ionic conductivity in various $\mathrm{Ba}_{3} \mathrm{NbMo}_{1-x} \mathrm{~W}_{x} \mathrm{O}_{8.5}(0 \leq x \leq 1)$ phases. ${ }^{2}$, 
${ }^{17-19}$ However, determination of site occupancies in these materials have mainly been based on neutron and synchrotron x-ray powder diffraction data, and the only single-crystal structure determinations reported to date utilised laboratory x-ray diffraction, ${ }^{15}$ which has limited sensitivity to oxygen in the presence of heavy metals. Here we report the first structure determination from single-crystal neutron diffraction data of a $\mathrm{Ba}_{3} \mathrm{M}_{2} \mathrm{O}_{8.5 \pm \delta}$-type conductor, $\mathrm{Ba}_{3} \mathrm{NbWO}_{8.5}$, yielding insights into both cation and anion disorder. We combine these results with an interpretation of calculated $\mathrm{O}^{2-}$ energy landscapes that sheds new light on the relationship between ionic conductivity, $\mathrm{O}$ site distributions and cation choice in this material and its analogues.

\section{Experimental Section}

Polycrystalline $\mathrm{Ba}_{3} \mathrm{NbWO}_{8.5}$ was prepared by conventional solid-state synthesis from a stoichiometric mixture of $\mathrm{BaCO}_{3}, \mathrm{Nb}_{2} \mathrm{O}_{5}$ and $\mathrm{WO}_{3}$. Reagents were dried at $1000{ }^{\circ} \mathrm{C}\left(\mathrm{Nb}_{2} \mathrm{O}_{5}\right)$ or $400{ }^{\circ} \mathrm{C}$ (others) overnight before use. The mixture was formed into an ethanol slurry and ground in agate media using a planetary ball mill at $285 \mathrm{rpm}$ for $45 \mathrm{~min}$. The ethanol was allowed to evaporate in air before the milled powders were transferred to an alumina crucible and calcined at $900{ }^{\circ} \mathrm{C}$ for $12 \mathrm{~h}$. The sample was then reground by hand using an agate mortar and pestle and annealed at $1200{ }^{\circ} \mathrm{C}$ for a further $12 \mathrm{~h}$. Cylindrical sample rods approximately $6 \mathrm{~mm}$ in diameter and $100 \mathrm{~mm}$ in length were prepared by sealing the powder in rubber tubes and pressing at $50 \mathrm{MPa}$ in a hydrostatic press. The resulting powder rods were sintered at $1500{ }^{\circ} \mathrm{C}$ for $9 \mathrm{~h}$ in air to increase their relative density.

Crystals of nominal composition $\mathrm{Ba}_{3} \mathrm{NbWO}_{8.5}$ were obtained by the floating-zone (FZ) method using an optical FZ furnace (Crystal Systems Corporation, FZ-T-10000-H-VIII-VPO-PC) equipped with four $150 \mathrm{~W}$ halogen lamps. The growth was performed under a $\sim 0.5 \mathrm{~L} \mathrm{~min}^{-1}$ flow of air at ambient pressure. The polycrystalline feed and seed rods were translated upwards through 
the stationary lamp focus at $4 \mathrm{~mm} \mathrm{~h}^{-1}$ while counter-rotating at $15 \mathrm{rpm}$. Stable crystallisation could not be maintained for long periods at translation rates slower than $4 \mathrm{~mm} \mathrm{~h}^{-1}$ due to the growth of a solid crust or "spurs" at the solid-liquid interface of the feed rod causing rapid depletion of material from the molten zone. After cooling, the solidified boule was visibly multi-phase as found previously ${ }^{15}$ but a mixture of colourless and opaque beige crystal fragments up to $\sim 1 \mathrm{~mm}$ in diameter could be distinguished under an optical microscope.

Time-of-flight neutron diffraction data were collected on the SXD diffractometer at ISIS Neutron and Muon Source, UK. The crystal fragment chosen for data collection was beige in colour and approximately spherical with a diameter of $\sim 1 \mathrm{~mm}$. The sample was encased in Al foil and mounted on a spindle made of adhesive Al sheet. The mounted sample was positioned inside a vacuum furnace with $\mathrm{Nb}$ heating elements in preparation for a non-ambient data collection sequence. Data frames with an integrated neutron flux of $1500 \mu \mathrm{A}$ were collected at 6 sample orientations spanning a $300^{\circ}$ rotation about the vertical axis. ${ }^{20}$

Data indexing, integration and reduction were performed using SXD2001. ${ }^{21}$ Using the expected unit cell, six distinct and well-separated reflection sets arising from different crystallites within the sample were indexed. Reflections were integrated using the line integral method in SXD2001. ${ }^{21}$ A V sphere standard measurement with empty instrument measurement was used to correct for detector efficiency and neutron flux distribution.

The structure of $\mathrm{Ba}_{3} \mathrm{NbWO}_{8.5}$ was refined against the neutron diffraction data using Jana2006. ${ }^{22}$ Lattice parameters determined previously from single-crystal x-ray diffraction at $290 \mathrm{~K}$ were used. ${ }^{15}$ Fractional occupancies at the mixed-metal sites M1 and M2 were constrained so that each site contained a 1:1 mixture of $\mathrm{Nb}$ and $\mathrm{W}$, the total occupancy of which was allowed to refine 
freely. No constraint was applied to the overall sum of occupancies at M1 and M2. Fractional occupancies of $\mathrm{Ba} 1, \mathrm{Ba} 2$ and $\mathrm{O} 1$ were fixed to unity, ${ }^{4}$ while those of the partially occupied $\mathrm{O} 2$ and O3 sites were allowed to refine without constraint. All atomic positional parameters not fixed by symmetry were refined freely. Anisotropic atomic displacement parameters (ADPs) were refined for all sites except the low-occupancy $\mathrm{O} 3$ site, for which a single isotropic ADP was refined. Further details of the structure refinements are presented in the Supporting Information.

Bond valence energy landscape (BVEL) maps for $\mathrm{O}^{2-}$ were calculated using 3DBVSMAPPER ${ }^{23}$ (version 2.02) with a grid spacing of $0.2 \AA$. In order to facilitate direct comparison between outputs generated using the same version of the software, BVEL maps were also recalculated for the structures of $\mathrm{Ba}_{3} \mathrm{NbMoO}_{8.5}$ and $\mathrm{Ba}_{3} \mathrm{NbWO}_{8.5}$ refined against single-crystal x-ray diffraction and reported in ref. ${ }^{15}$. Additional details of the input structures are contained in the Supporting Information.

Structural representations in all Figures were drawn using VESTA. ${ }^{24}$

\section{Results and Discussion}

The refined structure of $\mathrm{Ba}_{3} \mathrm{NbWO}_{8.5}$ is depicted in Figure 1, and crystallographic information is presented in tables $\mathrm{S} 1, \mathrm{~S} 2$ and $\mathrm{S} 3$ in the Supporting Information. The refined total $(\mathrm{Nb}, \mathrm{W})$ stoichiometry of 1.99(4) ions per formula unit is in excellent agreement with the expected value of 2, indicating that the true ratio of $\mathrm{Nb}: \mathrm{W}$ in the sample is likely to be $1: 1$. Although it is not possible to refine the relative abundances of two chemical species on a mixed site with an unknown vacancy fraction, the difference between the neutron coherent scattering lengths of $\mathrm{Nb}(7.05 \mathrm{fm})$ and $\mathrm{W}(4.86 \mathrm{fm})^{25}$ means that the refined fractional occupancies of the $\left(\mathrm{Nb}_{0.5} \mathrm{~W}_{0.5}\right)$ sites would be expected to yield a total $(\mathrm{Nb}, \mathrm{W})$ stoichiometry greater than 2 if the ratio $\mathrm{Nb}: \mathrm{W}$ in the measured 
sample was greater than $1: 1$, and vice versa. It has been shown previously ${ }^{15}$ that the $\mathrm{Ba}_{3} \mathrm{NbWO}_{8.5}$ structure can accommodate a maximum of 2 cations per trimer unit due to the close spacing of the $\mathrm{M} 1$ and M2 sites, yielding a maximum physically achievable $(\mathrm{Nb}, \mathrm{W})$ stoichiometry of 2 ions per formula unit. While our refinement result does not rule out the possibility of $(\mathrm{Nb}, \mathrm{W})<2$ in conjunction with $\mathrm{Nb}: \mathrm{W}>1: 1$, we note that no evidence for cation sub-stoichiometry has been presented in any prior studies of $\mathrm{Ba}_{3} \mathrm{NbWO}_{8.5}$ or related isostructural materials. ${ }^{26}$
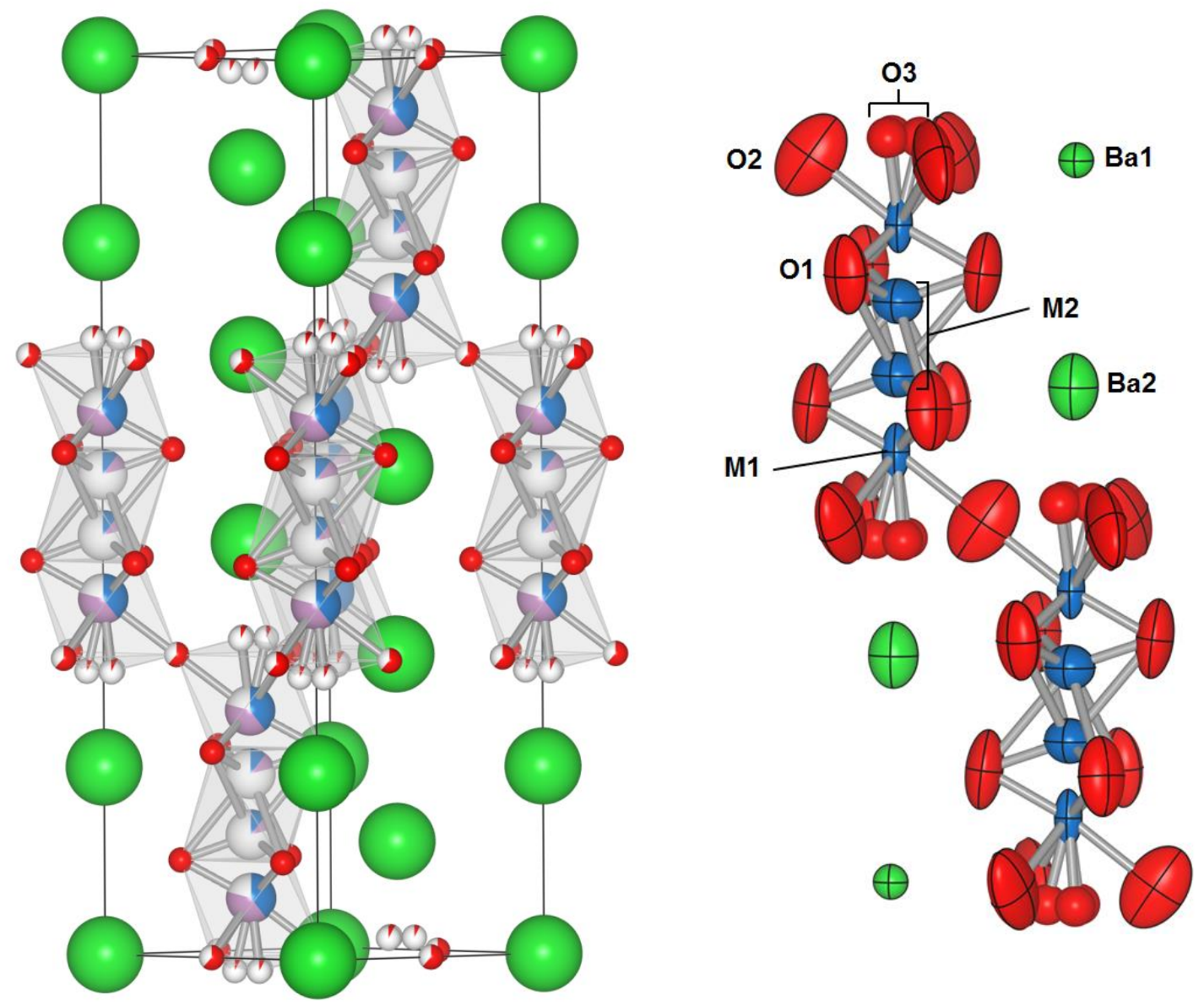

Figure 1. (a) The structure of $\mathrm{Ba}_{3} \mathrm{NbWO}_{8.5}$ refined against single-crystal neutron diffraction data (Ba: green, $\mathrm{Nb}$ : blue, $\mathrm{W}$ : purple, $\mathrm{O}$ : red). The fractional occupancies of mixed or partially vacant sites are represented as pie charts with the white sector representing the fraction of site 
vacancies. (b) Detail of the refined structure showing two trimer units. The ADP ellipsoids are drawn to $95 \%$ probability.

The fractional site occupancies refined with $\mathrm{Nb}: \mathrm{W}=1: 1$ enforced at the $\mathrm{M} 1$ and $\mathrm{M} 2$ sites show that $20.6(12) \%$ of these cations are located at the M2 site in the central octahedron of the trimer. This result is in excellent agreement with a previous single-crystal x-ray diffraction study that reported 20.3(3)\% of $(\mathrm{Nb}, \mathrm{W})$ cations occupying $\mathrm{M} 2$, also assuming equal numbers of both species at the site. ${ }^{15}$ Although the assumption of a statistical mixture of Nb and $\mathrm{W}$ on the M1 and M2 sites has not been tested experimentally, the close agreement between the occupancies obtained from $\mathrm{x}$-ray and neutron diffraction studies strongly suggests that the assumption is correct. X-rays are scattered more strongly by $\mathrm{W}^{6+}$ than by $\mathrm{Nb}^{5+}$ but neutrons are scattered more strongly by $\mathrm{Nb}$ than by $\mathrm{W}$, so a deviation of the real $\mathrm{Nb}: \mathrm{W}$ ratio from 1:1 would be expected to bias the occupancies refined against the x-ray and neutron diffraction data sets oppositely. Statistical analysis of cation coordination environments in known oxides has shown that $\mathrm{Nb}^{5+}$ and $\mathrm{W}^{6+}$ exhibit similar patterns of preference for octahedral coordination geometry, ${ }^{27}$ so a significant difference between their respective distributions over the $\mathrm{M} 1$ and $\mathrm{M} 2$ sites in $\mathrm{Ba}_{3} \mathrm{NbWO}_{8.5}$ is not expected.

The relative occupancies of the $\mathrm{O} 2$ and $\mathrm{O} 3$ sites have been the focus of much discussion in previous studies of $\mathrm{Ba}_{3} M_{2} \mathrm{O}_{8.5 \pm \delta}$-type materials due to their reported correlation with oxide-ionic conductivity. ${ }^{2,17-19}$ In the present work, the $\mathrm{O} 2$ and $\mathrm{O} 3$ site occupancies were refined independently without any constraint on the overall sum, resulting in an overall stoichiometry of 8.31(4) O per formula unit assuming full occupancy of the $\mathrm{O} 1$ site. The slight oxygen deficiency with respect to the nominal $\mathrm{O}$ stoichiometry of 8.5 may be attributed to several possible factors, which are discussed below. 
(1) Oxygen deficiency in the sample due to cation vacancies and/or a Nb:W ratio greater than 1 . As discussed above, our refinement results suggest that both of these conditions would need to exist simultaneously in order to achieve the very close agreement observed between the refined total cation occupancy and the expected value. Although this scenario is permitted by our refinement results, there is no other positive evidence in our work or the existing literature to support cation vacancies in $\mathrm{Ba}_{3} \mathrm{NbWO}_{8.5}$.

(2) Oxygen deficiency in the sample due to reduction. The high-temperature conditions and relatively fast cooling rate during the $\mathrm{FZ}$ growth of $\mathrm{Ba}_{3} \mathrm{NbWO}_{8.5}$ crystals presents the possibility of partial reduction of $\mathrm{Mo}^{6+}$ or $\mathrm{Nb}^{5+}$ occurring and persisting to room temperature. The light brown colour of the sample may also be considered to support this view. Yashima et al. observed a mass loss in thermogravimetric (TGA) measurements of polycrystalline $\mathrm{Ba}_{3} \mathrm{NbMoO}_{8.5}$ corresponding to the loss of $\sim 0.13 \mathrm{O}$ upon heating the sample to $800{ }^{\circ} \mathrm{C}$ in air. ${ }^{26}$ However, a subsequent TGA-mass spectrometry (TGA-MS) experiment conducted under similar conditions suggested that water was the primary species evolved. ${ }^{16}$ Partial reduction of $\mathrm{Ba}_{3} \mathrm{NbMoO}_{8.5}$ at $600{ }^{\circ} \mathrm{C}$ has been demonstrated under actively reducing conditions, ${ }^{3}$ but to our knowledge, no experimental data on the redox behaviour of $\mathrm{Ba}_{3} \mathrm{NbWO}_{8.5}$ in air up to its melting point $\left(\sim 1650^{\circ} \mathrm{C}\right)$ have been reported.

(3) Positional disorder of $\mathrm{O}$ ions resulting in some nuclear density not being captured by the refined $\mathrm{O} 2$ and $\mathrm{O} 3$ crystallographic sites. Oxygen disorder was predicted in reference ${ }^{15}$ on the basis of large and elongated refined ADPs at the $\mathrm{O} 2$ sites in $\mathrm{Ba}_{3} \mathrm{NbMoO}_{8.5}$ and structural considerations relating to irregular local coordination geometries that would likely be imposed by vacancies at the corner-shared $\mathrm{O} 2$ sites. Chambers et al. ${ }^{16}$ later demonstrated the existence of considerable $\mathrm{O}$ disorder in $\mathrm{Ba}_{3} \mathrm{NbMoO}_{8.5}$ by observing highly variable $\mathrm{M} 1$ coordination environments in neutron total scattering and pair distribution function (PDF) analysis. In the 
present work on $\mathrm{Ba}_{3} \mathrm{NbWO}_{8.5}$, the refined $\mathrm{O} 2$ site ADPs are again large $\left(U_{\text {equiv }}=0.52(4) \AA^{2}\right)$ in comparison to the other atomic sites, but smaller than those determined for $\mathrm{Ba}_{3} \mathrm{NbMoO}_{8.5}$ in the single-crystal x-ray diffraction study $\left(0.67(9) \AA^{2}\right)^{15}$. Figure $1(\mathrm{~b})$ also shows that the orientation of the elongated ADP ellipsoid is roughly perpendicular to the $\mathrm{O} 2-\mathrm{M} 1$ bonds, as is typical for thermal vibrations in metal-oxygen polyhedra, in contrast to $\mathrm{Ba}_{3} \mathrm{NbMoO}_{8.5}$ where the O2 ADP ellipsoid was elongated along the pathway between neighbouring $\mathrm{O} 3$ sites. ${ }^{15}$ A nuclear density Fourier difference map, calculated for $\mathrm{Ba}_{3} \mathrm{NbWO}_{8.5}$ after removing the $\mathrm{O} 2$ and $\mathrm{O} 3$ atoms from the structure model, shows a well-defined peak corresponding to the location of the O2 site (Figure 2(a)). However, the low-occupancy $\mathrm{O} 3$ site could not be distinguished above the noise in this density map. After recalculating the Fourier difference map with the refined $\mathrm{O} 2$ site included in the structure model, a region of high density with three-fold symmetry corresponding to the off-axis split $\mathrm{O} 3$ site was weakly discernible (Figure 2(b)). The shapes of these Fourier maxima show that using discrete $\mathrm{O} 2$ and $\mathrm{O} 3$ sites to describe the distribution of oxygen in $\mathrm{Ba}_{3} \mathrm{NbWO}_{8.5}$ is acceptable, and that there is no clear evidence for a significant distribution of disordered oxygen along diffusion pathways in this material at room temperature. Nevertheless, because the quantity of "unaccounted" oxygen (0.19(4) per formula unit) is much less than the amount refined at the O3 site (0.46(3) per formula unit), it would probably not be detectable above the noise in our Fourier difference maps if it is present within the material. 
(a)
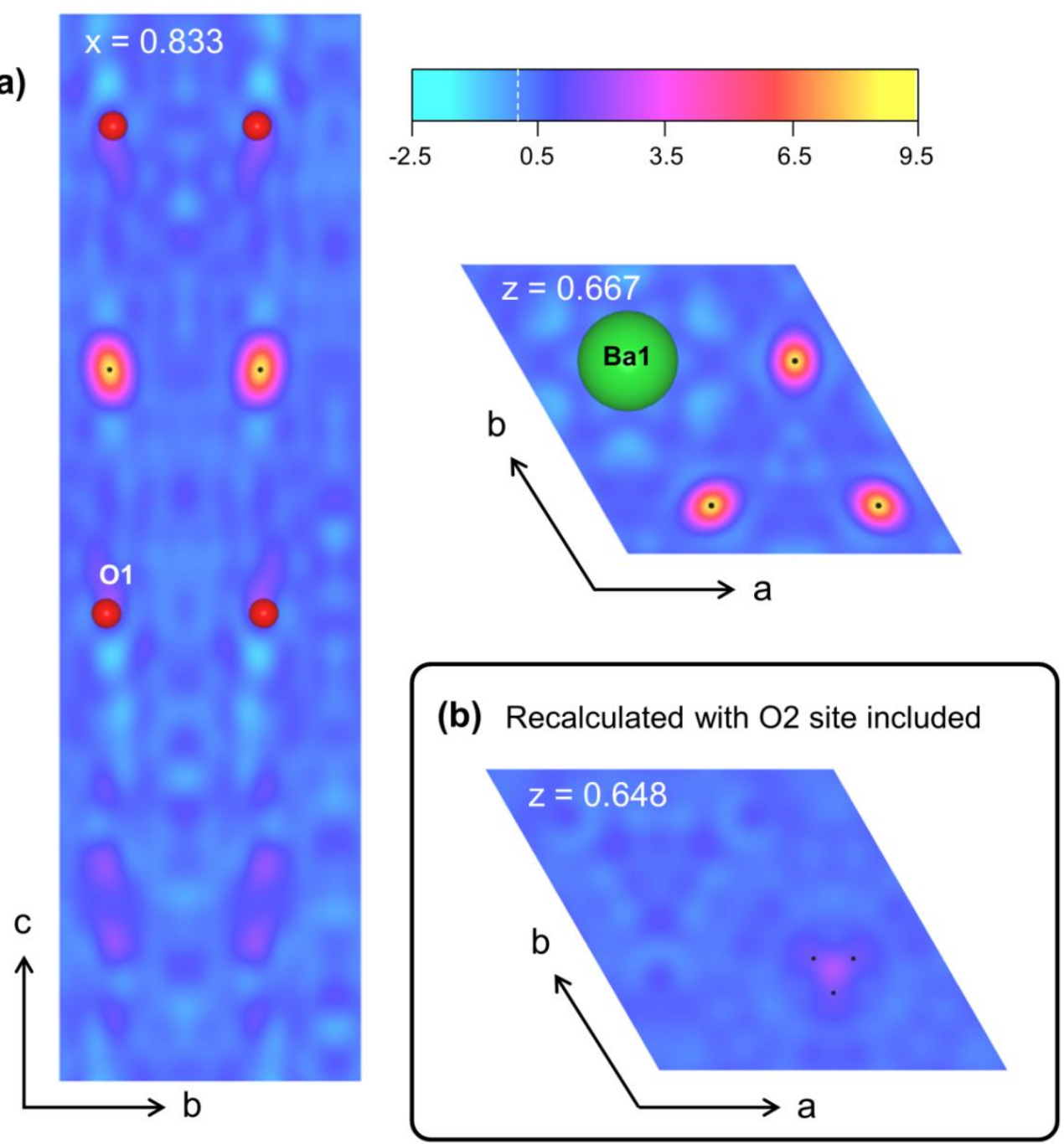

Figure 2. (a) Sections of a Fourier difference map calculated after deleting the $\mathrm{O} 2$ and $\mathrm{O} 3$ sites from the $\mathrm{Ba}_{3} \mathrm{NbWO}_{8.5}$ structure refined against single-crystal neutron diffraction data. Black dots show the positions of $\mathrm{O} 2$ sites. (b) Section of a Fourier difference map calculated with only the O3 site deleted from the structure. Black dots show the refined position of O3.

Of the 2.31(5) oxygen atoms occupying $\mathrm{O} 2$ and $\mathrm{O} 3$ sites, $80(2) \%$ were located at $\mathrm{O} 2$, compared with $91 \%$ determined previously from free refinement against neutron powder diffraction data ${ }^{28}$ at room temperature. Assigning the "missing" 0.19 formula units of oxygen to the $\mathrm{O} 2$ site does not account for this discrepancy, as it would only increase the $\mathrm{O} 2$ fraction in our sample to $82 \%$. In 
the archetypal $\mathrm{Ba}_{3} M_{2} \mathrm{O}_{8.5 \pm \delta}$ structure model with $\mathrm{O} 2(9 \mathrm{e})$ and $\mathrm{O} 3$ (18h / 3 mutually exclusive) both $50 \%$ occupied, the $\mathrm{O} 2$ sites accommodate $60 \%$ of oxygen in the layer. It is therefore clear that our results support the prevailing view that $\mathrm{O} 2$ occupancy dominates the $\mathrm{O} 2 / \mathrm{O} 3$ layer in $\mathrm{Ba}_{3} \mathrm{NbWO}_{8.5}$ to a greater degree than in $\mathrm{Ba}_{3} \mathrm{NbMoO}_{8.5},{ }^{1,} 17,28-29$ even if the extent of $\mathrm{O} 2$ occupation differs slightly from previous reports. It has been noted that high occupancy of the corner-shared $\mathrm{O} 2$ site in this material is probably related to the stronger preference of $\mathrm{W}^{6+}$ to adopt 6-fold coordination in comparison with $\mathrm{Mo}^{6+}$, which is found in tetrahedral environments more frequently than $\mathrm{W}^{6+} .27$ Although we have argued that interpreting the $\mathrm{O} 2 / \mathrm{O} 3$ occupancy distribution simply as a "ratio of octahedra to tetrahedra" is inaccurate due to the high degree of ionic disorder necessary to satisfy stoichiometry and local geometry, ${ }^{15-16}$ the link between "variable" or "flexible" M1 coordination geometry (i.e. significant localised or delocalised disorder of ions between $\mathrm{O} 2$ and $\mathrm{O} 3$ sites) and ionic conductivity in $\mathrm{Ba}_{3} M_{2} \mathrm{O}_{8.5 \pm \delta}$-type conductors is clear, as has been recognised in other oxide ion conductors. ${ }^{9}, 30-31$

Some insight into the causal relationship between relatively high O3 occupancy and superior ionic conductivity in these materials can be gained by considering the $\mathrm{O}^{2-}$ positional energy landscape, which is well approximated using easily-calculated BVEL maps. ${ }^{23}$ Fop et al. showed that a curved minimum-energy $\mathrm{O}^{2-}$ conduction pathway (valley) connects nearest-neighbouring O2 sites via a saddle point near O3, and noted a correlation between the activation energy barrier at this saddle point and refined $\mathrm{O} 2 / \mathrm{O} 3$ occupancies among a series of $\mathrm{Ba}_{3}(\mathrm{Nb}, \mathrm{V}) \mathrm{MoO}_{8.5}$ conductors and $\mathrm{Ba}_{3} \mathrm{NbWO}_{8.5}{ }^{4}$ The general features of this conduction pathway, including a local energy minimum at or very near the $\mathrm{O} 2$ site and a saddle point near the split $\mathrm{O} 3$ site, are corroborated by BVEL maps calculated for our refined structure of $\mathrm{Ba}_{3} \mathrm{NbWO}_{8.5}$ (Figure 3). The minimum and saddle point energies are shown alongside those calculated for previously refined 
structures ${ }^{15}$ in Table 1. These absolute energies show a clear qualitative correlation with patterns of refined site occupancies established over multiple studies (i.e. the $\mathrm{O} 2$ and $\mathrm{O} 3$ sites in $\mathrm{Ba}_{3} \mathrm{NbWO}_{8.5}$ having higher and lower occupancy, respectively, than in $\left.\mathrm{Ba}_{3} \mathrm{NbMoO}_{8.5}\right)^{1}{ }^{1}$ 17, 28-29 Because lattice oxygen is omitted during a typical oxide BVEL calculation, the calculated energy landscape is derived from the cation lattice only and cannot be influenced by $\mathrm{O}$ site occupancies. Rather than considering high $\mathrm{O} 3$ occupancy to facilitate low-energy conduction pathways, ${ }^{4}$ we instead propose that the energy difference between the $\mathrm{O} 2$ and $\mathrm{O} 3$ sites is the cause, not the consequence, of the relative site occupancies observed experimentally. The presence of cations whose geometric and bonding preferences favour occupation of the $\mathrm{O} 3$ site will result in a lower saddle point energy and thus a lower barrier to $\mathrm{O}^{2-}$ diffusion, leading to both increased ionic conductivity and higher occupation of $\mathrm{O} 3$. We also note that the position of the $\mathrm{O} 3$ site at the maximum of the diffusion pathway energy profile $e^{4}$ implies that the presence of any oxygen at this site necessitates a continuous distribution of ions along the pathway, even if the density of that distribution is low. The fact that the $\mathrm{O} 3$ site was not discernible in our Fourier difference maps (Figure 2) until the $\mathrm{O} 2$ site was reinstated, after which any residual nuclear density beyond the effective limit of the $\mathrm{O} 2 \mathrm{ADP}$ would appear as a discrete peak, is consistent with this view. 


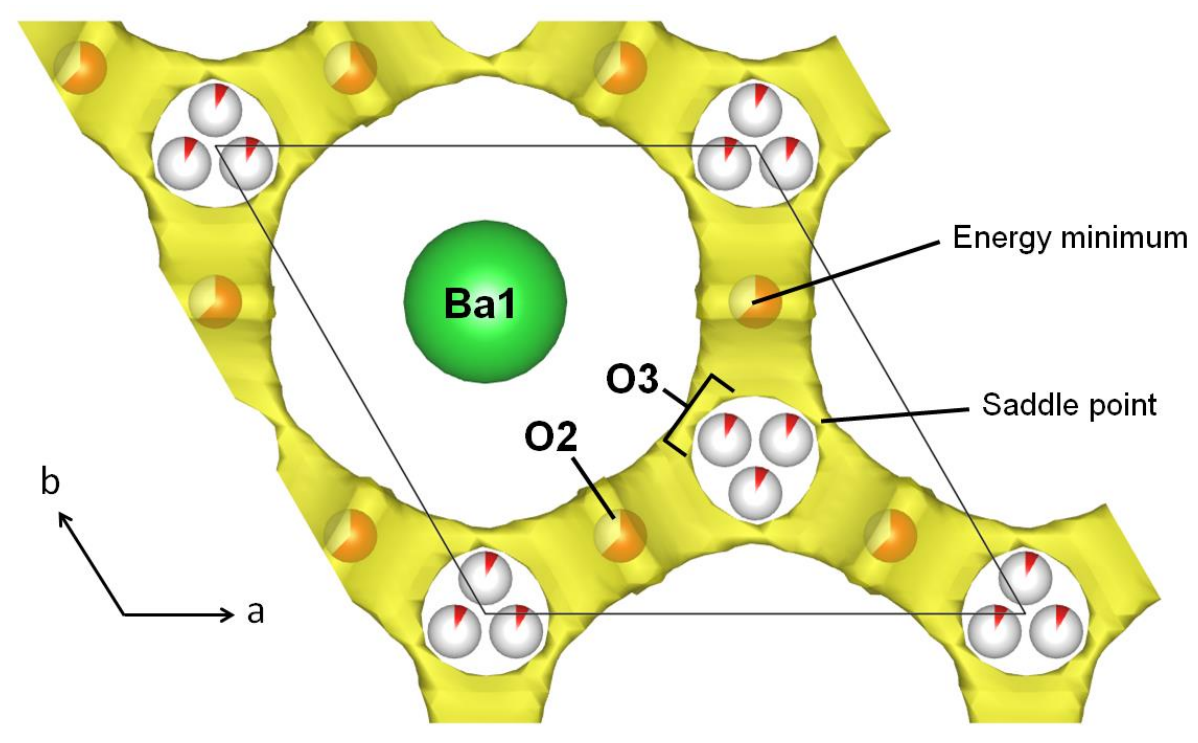

Figure 3. Section of a BVEL map calculated for $\mathrm{Ba}_{3} \mathrm{NbWO}_{8.5}$ and drawn at an isosurface level of $-3.50 \mathrm{eV}$. Text labels indicate the approximate locations of key features in the energy landscape.

\begin{tabular}{l|lll}
\hline & Ba3NbWO8.5 & Ba3NbWO8.5 & Ba3NbMoO8.5 \\
\hline Refined structure from: & $\begin{array}{l}\text { single-crystal } \\
\text { neutron diffraction }\end{array}$ & $\begin{array}{l}\text { single-crystal } \\
\text { X-ray diffraction }\end{array}$ & single-crystal \\
& -5.20 & -5.16 & X-ray diffraction $^{15}$ \\
Minimum $(\mathrm{eV})^{\mathrm{a}}$ & -3.75 & -3.77 & -4.78 \\
Saddle point $(\mathrm{eV})^{\mathrm{b}}$ & 1.45 & 1.39 & -3.92 \\
Difference $(\mathrm{eV})$ & & & 0.86 \\
\hline
\end{tabular}

${ }^{\mathrm{a}}$ At or very near the $\mathrm{O} 2$ site. ${ }^{\mathrm{b}}$ Near the $\mathrm{O} 3$ site.

Table 1. Energies of minima and saddle points along the conduction pathways in BVEL maps calculated for refined structures of $\mathrm{Ba}_{3} \mathrm{NbWO}_{8.5}$ and $\mathrm{Ba}_{3} \mathrm{NbMoO}_{8.5}$. See the Supplementary Information for more details of structures used in the BVEL calculations.

The structural chemistry of the $\mathrm{Ba}_{3} M_{2} \mathrm{O}_{8.5 \pm \delta}$ conductors is complex, and a full understanding of the oxide ion migration pathways and conductivity mechanisms will require good-quality ab initio computational studies of these materials. Although non-trivial due to the complexity and size of 
the simulation model and the trajectories needed, such computational studies are possible and, especially when interpreted in conjunction with experimental methods, they can provide qualitative and quantitative insight into oxide ion dynamics in structurally complex materials. ${ }^{30-37}$

\section{Conclusions}

The structure of a $\mathrm{Ba}_{3} M_{2} \mathrm{O}_{8.5 \pm \delta}$-type material has been refined against single-crystal neutron diffraction data for the first time. The refinements confirm the disordered cation arrangement with $20.6 \%$ of the $(\mathrm{Nb}, \mathrm{W})$ cations located at the M2 site, which is strongly displaced away from the octahedron centre. Comparison with published x-ray diffraction experiments allows us to deduce that the material is stoichiometric with respect to cations, and that $\mathrm{Nb}$ and $\mathrm{W}$ exhibit similar M1/M2 site selectivities. The apparent oxygen sub-stoichiometry of 0.19(4) O per formula unit may arise from either a small amount of ionic disorder or actual oxygen deficiency due to mechanisms discussed in the text. Unconstrained refinement of $\mathrm{O}$ occupancies in the $\mathrm{O} 2 / \mathrm{O} 3$ layer shows that $80 \%$ of oxide ions in this layer occupy O2-type sites. Consideration of calculated bond valence energy landscapes suggests that the well-established correlation between O3 occupancy and good ionic conductivity exists because both arise from the energy landscape dictated by the cations present in the structure. The energy profile of the $\mathrm{O} 2-\mathrm{O} 3-\mathrm{O} 2$ conduction pathway also suggests that a continuous low-density distribution of oxide ions probably exists even in $\mathrm{Ba}_{3} \mathrm{NbWO}_{8.5}$, though nuclear density peaks in Fourier difference maps show that refining localised $\mathrm{O} 2$ and $\mathrm{O} 3$ sites serves as an adequate model of $\mathrm{Ba}_{3} \mathrm{NbWO}_{8.5}$ at room temperature. Our results offer new insight into the causal mechanism of oxide-ionic diffusion in $\mathrm{Ba}_{3} M_{2} \mathrm{O}_{8.5 \pm \delta}$-type conductors, and help to rationalise the influence of cation choice in engineering optimal ionic conductivity in these materials. 


\section{ASSOCIATED CONTENT}

\section{Supporting Information.}

The following files are available free of charge.

PDF document containing further details of structure refinements and bond valence energy landscape map calculations and crystallographic data tables

\section{AUTHOR INFORMATION}

\section{Corresponding Author}

*josie.auckett@durham.ac.uk

\section{Author Contributions}

All authors have given approval to the final version of the manuscript.

\section{Funding Sources}

This work was supported by the Engineering and Physical Sciences Research Council (EP/P020534/1). J.E.A. acknowledges the support of a Newton International Fellowship (NF170809) awarded by The Royal Society.

\section{REFERENCES}

(1) McCombie, K. S.; Wildman, E. J.; Ritter, C.; Smith, R. I.; Skakle, J. M. S.; McLaughlin, A. C. Relationship between the Crystal Structure and Electrical Properties of Oxide Ion Conducting $\mathrm{Ba}_{3} \mathrm{~W}_{1.2} \mathrm{Nb}_{0.8} \mathrm{O}_{8.6 .}$ Inorg. Chem. 2018, 57 (19), 11942-11947.

(2) Fop, S.; McCombie, K. S.; Wildman, E. J.; Skakle, J. M. S.; McLaughlin, A. C. Hexagonal perovskite derivatives: a new direction in the design of oxide ion conducting materials. Chem. Commun. 2019, 55 (15), 2127-2137. 
(3) Fop, S.; Skakle, J. M. S.; McLaughlin, A. C.; Connor, P. A.; Irvine, J. T. S.; Smith, R. I.; Wildman, E. J. Oxide Ion Conductivity in the Hexagonal Perovskite Derivative $\mathrm{Ba}_{3} \mathrm{MoNbO}_{8.5} . J$. Am. Chem. Soc. 2016, 138 (51), 16764-16769.

(4) Fop, S.; McCombie, K.; Smith, R. I.; McLaughlin, A. C. Enhanced Oxygen Ion Conductivity and Mechanistic Understanding in $\mathrm{Ba}_{3} \mathrm{Nb}_{1-\mathrm{x}} \mathrm{V}_{\mathrm{x}} \mathrm{MoO}_{8.5}$. Chem. Mater. 2020, 32 (11), 4724-4733. (5) Cao, Y.; Duan, N.; Wang, X.; Chi, B.; JianPu; Jian, L. Enhanced electrical conductivity of Mo-doped LaNbO4. J. Eur. Ceram. Soc. 2015, 35 (6), 1979-1983.

(6) Li, C.; Bayliss, R. D.; Skinner, S. J. Crystal structure and potential interstitial oxide ion conductivity of $\mathrm{LnNbO}_{4}$ and $\mathrm{LnNb}_{0.92} \mathrm{~W}_{0.08} \mathrm{O}_{4.04}(\mathrm{Ln}=\mathrm{La}, \mathrm{Pr}, \mathrm{Nd})$. Solid State Ionics 2014, 262, $530-535$

(7) Leon-Reina, L.; Losilla, E. R.; Martinez-Lara, M.; Martin-Sedeno, M. C.; Bruque, S.; Nunez, P.; Sheptyakov, D. V.; Aranda, M. A. G. High oxide ion conductivity in Al-doped germanium oxyapatite. Chem. Mater. 2005, 17 (3), 596-600.

(8) Tate, M. L.; Blom, D. A.; Avdeev, M.; Brand, H. E. A.; McIntyre, G. J.; Vogt, T.; Evans, I. R. New Apatite-Type Oxide Ion Conductor, $\mathrm{Bi}_{2} \mathrm{La}_{8}\left[\left(\mathrm{GeO}_{4}\right)_{6}\right] \mathrm{O}_{3}$ : Structure, Properties, and Direct Imaging of Low-Level Interstitial Oxygen Atoms Using Aberration-Corrected Scanning Transmission Electron Microscopy. Adv. Funct. Mater. 2017, 27 (8).

(9) Fuller, C. A.; Berrod, C.; Frick, B.; Johnson, M. R.; Clark, S. J.; Evans, J. S. O.; Evans, I. R. Brownmillerite-Type $\mathrm{Sr}_{2} \mathrm{ScGaO}_{5}$ Oxide Ion Conductor: Local Structure, Phase Transition, and Dynamics. Chem. Mater. 2019, 31 (18), 7395-7404.

(10) Fuller, C. A.; Berrod, Q.; Frick, B.; Johnson, M. R.; Avdeev, M.; Evans, J. S. O.; Evans, I. R. Oxide Ion and Proton Conductivity in Highly Oxygen-Deficient Cubic Perovskite $\mathrm{SrSc}_{0.3} \mathrm{Zn}_{0.2} \mathrm{Ga}_{0.5} \mathrm{O}_{2.4}$. Chem. Mater. 2020, 32 (10), 4347-4357. 
(11) Lacorre, P.; Goutenoire, F.; Bohnke, O.; Retoux, R.; Laligant, Y. Designing fast oxide-ion conductors based on $\mathrm{La}_{2} \mathrm{Mo}_{2} \mathrm{O}_{9}$. Nature 2000, 404 (6780), 856-858.

(12) Li, M.; Pietrowski, M. J.; De Souza, R. A.; Zhang, H.; Reaney, I. M.; Cook, S. N.; Kilner, J. A.; Sinclair, D. C. A family of oxide ion conductors based on the ferroelectric perovskite $\mathrm{Na}_{0.5} \mathrm{Bi}_{0.5} \mathrm{TiO}_{3}$. Nature Materials 2014, 13 (1), 31-35.

(13) Kuang, X.; Green, M. A.; Niu, H.; Zajdel, P.; Dickinson, C.; Claridge, J. B.; Jantsky, L.; Rosseinsky, M. J. Interstitial oxide ion conductivity in the layered tetrahedral network melilite structure. Nature Materials 2008, 7 (6), 498-504.

(14) Kuang, X.; Payne, J. L.; Johnson, M. R.; Evans, I. R. Remarkably High Oxide Ion Conductivity at Low Temperature in an Ordered Fluorite-Type Superstructure. Angewandte Chemie-International Edition 2012, 51 (3), 690-694.

(15) Auckett, J. E.; Milton, K. L.; Evans, I. R. Cation distributions and anion disorder in $\mathrm{Ba}_{3} \mathrm{NbMO}_{8.5}(M=\mathrm{Mo}, \mathrm{W})$ materials: Implications for oxide ion conductivity. Chem. Mater. 2019, 31 (5), 1715-1719.

(16) Chambers, M. S.; McCombie, K. S.; Auckett, J. E.; McLaughlin, A. C.; Irvine, J. T. S.; Chater, P. A.; Evans, J. S. O.; Evans, I. R. Hexagonal perovskite related oxide ion conductor $\mathrm{Ba}_{3} \mathrm{NbMoO}_{8.5}$ : Phase transition, temperature evolution of the local structure and properties. $J$. Mater. Chem. A 2019, 7 (44), 25503-25510.

(17) Bernasconi, A.; Tealdi, C.; Malavasi, L. High-Temperature Structural Evolution in the $\mathrm{Ba}_{3} \mathrm{Mo}_{(1-x)} \mathrm{W}_{x} \mathrm{NbO}_{8.5}$ System and Correlation with Ionic Transport Properties. Inorg. Chem. 2018, $57(11), 6746-6752$. 
(18) Fop, S.; Wildman, E. J.; Irvine, J. T. S.; Connor, P. A.; Skakle, J. M. S.; Ritter, C.;

McLaughlin, A. C. Investigation of the Relationship between the Structure and Conductivity of the Novel Oxide Ionic Conductor $\mathrm{Ba}_{3} \mathrm{MoNbO}_{8.5}$. Chem. Mater. 2017, 29 (9), 4146-4152.

(19) Fop, S.; Wildman, E. J.; Skakle, J. M. S.; Ritter, C.; McLaughlin, A. C. Electrical and Structural Characterization of $\mathrm{Ba}_{3} \mathrm{Mo}_{1-x} \mathrm{Nb}_{1+x} \mathrm{O}_{8.5-x / 2}$ : The Relationship between Mixed Coordination, Polyhedral Distortion and the Ionic Conductivity of $\mathrm{Ba}_{3} \mathrm{MoNbO}_{8.5}$. Inorg. Chem. 2017, 56 (17), 10505-10512.

(20) Auckett, J.; Gutmann, M.; Evans, I., Correlations between crystallographic distributions and mobility of oxide ions in Ba3NbWO8.5. 2020, STFC ISIS Neutron and Muon Source. https://doi.org/10.5286/ISIS.E.RB2010447

(21) Gutmann, M. SXD2001 - a program for treating data from TOF neutron single-crystal diffraction. Acta Crystallogr. Sect. A 2005, 61 (a1), c164.

(22) Petříček, V.; Dušek, M.; Palatinus, L. Crystallographic Computing System JANA2006: General features. Z. Kristallogr. Cryst. Mater. 2014, 229 (5), 345.

(23) Sale, M.; Avdeev, M. 3DBVSMAPPER: a program for automatically generating bondvalence sum landscapes. J. Appl. Crystallogr. 2012, 45 (5), 1054-1056.

(24) Momma, K.; Izuma, F. VESTA: a three-dimensional visualization system for electronic and structural analysis. J. Appl. Crystallogr. 2008, 41, 653-658.

(25) Sears, V. F. Neutron scattering lengths and cross sections. Neutron News 1992, 3 (3), 26-37. (26) Yashima, M.; Tsujiguchi, T.; Fujii, K.; Niwa, E.; Nishioka, S.; Hester, J. R.; Maeda, K. Direct evidence for two-dimensional oxide-ion diffusion in the hexagonal perovskite-related oxide $\mathrm{Ba}_{3} \mathrm{MoNbO}_{8.5-\delta}$. J. Mater. Chem. A 2019, 7 (23), 13910-13916. 
(27) Waroquiers, D.; Gonze, X.; Rignanese, G.-M.; Welker-Nieuwoudt, C.; Rosowski, F.; Göbel, M.; Schenk, S.; Degelmann, P.; André, R.; Glaum, R.; Hautier, G. Statistical Analysis of Coordination Environments in Oxides. Chem. Mater. 2017, 29 (19), 8346-8360.

(28) McCombie, K. S.; Wildman, E. J.; Fop, S.; Smith, R. I.; Skakle, J. M. S.; McLaughlin, A. C. The crystal structure and electrical properties of the oxide ion conductor $\mathrm{Ba}_{3} \mathrm{WNbO}_{8.5}$. J. Mater. Chem. A 2018, 6 (13), 5290-5295.

(29) Bernasconi, A.; Tealdi, C.; Mühlbauer, M.; Malavasi, L. Synthesis, crystal structure and ionic conductivity of the $\mathrm{Ba}_{3} \mathrm{Mo}_{1-x} \mathrm{~W}_{x} \mathrm{NbO}_{8.5}$ solid solution. J. Solid State Chem. 2018, 258, 628633.

(30) Dunstan, M. T.; Halat, D. M.; Tate, M. L.; Evans, I. R.; Grey, C. P. Variable-Temperature Multinuclear Solid-State NMR Study of Oxide Ion Dynamics in Fluorite-Type Bismuth Vanadate and Phosphate Solid Electrolytes. Chem. Mater. 2019, 31 (5), 1704-1714.

(31) Peet, J. R.; Fuller, C. A.; Frick, B.; Zbiri, M.; Piovano, A.; Johnson, M. R.; Evans, I. R. Direct Observation of Oxide Ion Dynamics in $\mathrm{La}_{2} \mathrm{Mo}_{2} \mathrm{O}_{9}$ on the Nanosecond Timescale. Chem. Mater. 2017, 29 (7), 3020-3028.

(32) Kuang, X.; Payne, J. L.; Farrell, J. D.; Johnson, M. R.; Evans, I. R. Polymorphism and Oxide Ion Migration Pathways in Fluorite-Type Bismuth Vanadate, $\mathrm{Bi}_{46} \mathrm{~V}_{8} \mathrm{O}_{89}$. Chem. Mater. 2012, 24 (11), 2162-2167.

(33) Peet, J. R.; Chambers, M. S.; Piovano, A.; Johnson, M. R.; Evans, I. R. Dynamics in Bi(III)containing apatite-type oxide ion conductors: a combined computational and experimental study. J. Mater. Chem. A 2018, 6 (12), 5129-5135. 
(34) Peet, J. R.; Fuller, C. A.; Frick, B.; Koza, M. M.; Johnson, M. R.; Piovano, A.; Evans, I. R. Insight into Design of Improved Oxide Ion Conductors: Dynamics and Conduction Mechanisms in the $\mathrm{Bi}_{0.913} \mathrm{~V}_{0.087} \mathrm{O}_{1.587}$ Solid Electrolyte. J. Am. Chem. Soc. 2019, 141 (25), 9989-9997. (35) Pramana, S. S.; Baikie, T.; An, T.; Tucker, M. G.; Wu, J.; Schreyer, M. K.; Wei, F.; Bayliss, R. D.; Kloc, C. L.; White, T. J.; Horsfield, A. P.; Skinner, S. J. Correlation of Local Structure and Diffusion Pathways in the Modulated Anisotropic Oxide Ion Conductor $\mathrm{CeNbO}_{4.25}$. J. Am. Chem. Soc. 2016, 138 (4), 1273-1279.

(36) Wind, J.; Mole, R. A.; Ling, C. D. Oxygen Dynamics in Transition Metal-Doped Bismuth Oxides. Journal of Physical Chemistry C 2019, 123 (26), 15877-15884.

(37) Wind, J.; Mole, R. A.; Yu, D.; Ling, C. D. Liquid-like Ionic Diffusion in Solid Bismuth Oxide Revealed by Coherent Quasielastic Neutron Scattering. Chem. Mater. 2017, 29 (17), 7408-7415. 
For Table of Contents Only

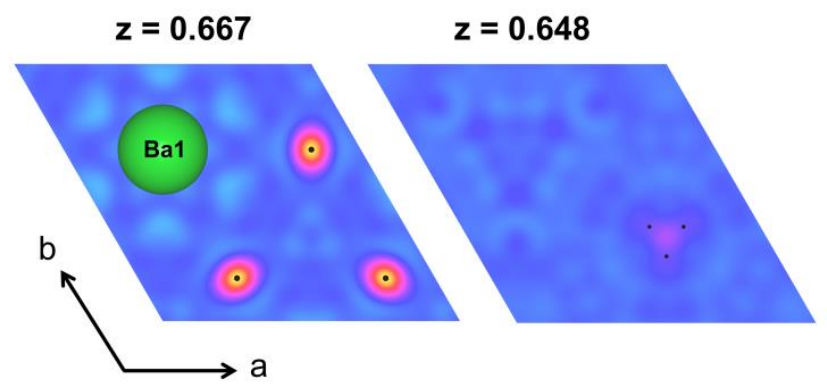

Single-crystal neutron diffraction data for $\mathrm{Ba}_{3} \mathrm{NbWO}_{8.5}$ and bond valence energy landscape calculations yield insights into the structural origins of competitive ionic conductivity in disordered $\mathrm{Ba}_{3} M_{2} \mathrm{O}_{8.5 \pm \delta}$-type materials. 